Grassroots Solutions for Improving Off-Reserve Access to Medical Transportation Funding

\author{
Michael Hankard \\ University of Sudbury
}

aboriginal policy studies Vol. 3, no. 1\&2, 2014, pp. 164-177

This article can be found at:

http://ejournals.library.ualberta.ca/index.php/aps/article/view/21703

ISSN: $1923-3299$

Article DOI: http://dx.doi.org/10.5663/aps.v3i1-2.21703

aboriginal policy studies is an online, peer-reviewed and multidisciplinary journal that publishes original, scholarly, and policy-relevant research on issues relevant to Métis, non-status Indians and urban Aboriginal people in Canada. For more information, please contact us at apsjournal@ualberta.ca or visit our website at www.ualberta.ca/nativestudies/aps/.

UNIVERSITY OF ALBERTA

FACULTY OF NATIVE STUDIES
Aboriginal Affairs and

Northern Development Canada

Affaires autochtones et Développement du Nord Canada 


\section{Grassroots Solutions for Improving Off-Reserve Access to Medical Transportation Funding}

Michael Hankard

University of Sudbury

\section{Introduction}

Since the 1990s, the Canadian federal government has provided medical transportation funding to status First Nations people through Health Canada's Non-Insured Health Benefits (NIHB) program. Within this program, transportation funding is available for registered status Indians who seek access to traditional healers (Health Canada 2005). This funding is officially available to those living either on- or off-reserve. However, in actual practice, obtaining this funding is much more difficult off reserve. In Ontario, where roughly 70 percent of band members live off-reserve (StatsCanada 2006), I wondered: How can access to this form of health care be primarily limited to the 30 percent living on onreserve? Motivated by this question, I began investigating how off-reserve access to NIHB medical transportation funding to see traditional healers is socially organized, and what actually happens when people living off-reserve try and access it.

The question grew into my dissertation, an interdisciplinary study that drew upon the research approaches of institutional ethnography and Indigenous knowledge. I conducted my investigation off-reserve along the Highway 17 corridor in northeastern Ontario that runs between Sault Ste Marie and Sudbury. The research methods used in my study included textual analysis, a medicine circle, and twenty-one interviews with applicants, front line workers, elders, healers, and regulated health professionals. It was important for me to use an interdisciplinary approach in this study because Indigenous knowledge illustrates where colonization, poverty, and racism have damaged Anishinabek health, and institutional ethnography shows where health work is tied into wider institutional relations and mediated by official/regulatory texts. Institutional ethnography also seeks to explicate how health work experiences are "socially and institutionally shaped," instead of studying individuals or simply describing experiences, (Bresalier, Gillis, McClure, McCoy, et al. 2002 , xvi). Both approaches are located in "the lives of real persons as individuals and social beings, not in the world of ideas" (Wilson 2008, 60).

\section{The Recommendations}

The following section describes eight primary recommendations for improving the current state of access to travel funding to see traditional healers. In keeping with the dialogical character of my study ${ }^{1}$ and its goal of empowering First Nations people, these

1 This is important in a study taking up the standpoint of First Nations people, particularly when drawing from institutional ethnography as a research approach. D. Smith $(1999,96-130)$ emphasizes the necessity of preserving the dialogic character in explicating the social.

aboriginal policy studies, vol. 3, no. 1\&2, 2014 
recommendations have come from the study's participants. While my own critical analysis played a role in developing these recommendations, the voices of the study participants are key for an important reason. During interviews, an elder/healer I interviewed stressed the importance of going directly to the community to find out the community's "wants and needs" before trying to institute any program or services (Myeengun, interview, January 2010). This is important, he said, because too often the people at the top are unaware of what communities really need because they never bother to ask them. This usually leads to programs and policies being imposed on First Nations, instead of being community-driven. D. Smith $(1999,16)$ also cautions how "[a]s a system of control, the ruling relations have been particularly effective in ensuring that, in the main, whatever knowledge is produced is not oriented to the needs and interests of the mass of people, but to the needs and interests of ruling." Knowing this from firsthand experience, the recommendations in this chapter seek to avoid replicating that process. I have attempted to apply the spirit or intent of the elder's advice, and to avoid taking a "ruling" approach by privileging the voices and ideas of people who deal with these issues in their everyday lives, instead of interpreting or imposing my own ideas about what should be done.

\section{Confrontation and Relationship Building?}

Participants mentioned two commonly rooted strategies to procure travel funding, either for themselves or their clients. Both strategies advocate being tenacious and refusing to accept the finality of decisions made by those in authority; however, they differ in their use of confrontation as a means to carry this forward. It is important to note that these two strategies, although suggested by different individuals, are not mutually exclusive. The first strategy involves the use of direct verbal confrontation with NIHB and other workers when denied or refused services. The second strategy, in contrast, avoids direct verbal confrontation and instead uses persistence to open lines of communication between the two parties. According to participants, both strategies have been used with equal success.

The use of direct verbal confrontation, as articulated by participants, involves standing up to authority figures one may encounter in the process, such as doctors, band council chiefs, MSB workers, medical transportation clerks, or others. This way of communicating is "foreign" to Native people, and often difficult to do because they prefer to avoid direct confrontational approaches and maintain harmony. However, by standing up to authority figures and refusing to accept decisions as final, people have found that they were able to obtain travel funding for themselves or clients. Several front line workers (Amik, Benashi, M'Kwa, Asemma) and band members (M'Sheeken and Megis) who refused to accept decisions made by authority figures (including those at NIHB) found that arguing and persistence worked to secure travel funding.

The second strategy (Myeengun's approach; see Myeengun, interview, January 2010) avoids direct verbal confrontation and seeks to form a relationship with people with decision-making authority. Myeengun, who proposed this position, stated that fighting is ineffective because it makes people become defensive and try to justify their decisions- 
good, bad, or otherwise. Rather than confronting people, he said, one should form a relationship with them, as they see you as a person instead of an object when you do. Forming the relationship can take time, but involves "having tea" with people and believing "there is another way to handle this." The elder also said that even though you may be told that you can't have a particular service, this decision is not final and you can still gain the cooperation of the person in authority. Myeengun contended that people have to be persistent (just as in the first approach), and not be deterred by negative personalities or responses from workers. How to gain that cooperation is what differs between the first approach and this one.

Myeengun's approach requires that a person start thinking differently than people in First Nations communities are accustomed to. By being persistent and developing a relationship, a person can breach the barrier established by a lack of cooperation. Myeengun's approach emerged when he was a young man after witnessing elders in his own community just "lower their heads" and walk away after being told "No" by government officials or the band council. He saw that fighting with authority figures did not work to change these decisions either. To develop a relationship and initiate a dialogue, he now proposes bringing coffee and tea, initiating a dialogue, and speaking with people at all levels of management until they finally agree to talk and listen.

Individuals may also consider combining elements of the two strategies to achieve the ends they seek. For example, considering the different conceptions of time organization between First Nations and bureaucracies, a long-term commitment to forming a relationship with those in official positions can be pursued while, simultaneously, using confrontation to forward one's agenda. A sustained, long-term confrontational approach can be used while simultaneously seeking to open communication and engage in joint problem solving approaches.

\section{Two Forms of Advocacy}

\section{Advocating for Off-reserve Membership}

One thing that would be really cool for the bands to do if there was ever money for it would be to have a full-time advocacy worker on staff for band members whose job it would be to advocate in different areas for the off-reserve membership. (Benashi, interview, January 2010).

The participants in the project have asserted that band council forms of governance do not adequately represent off-reserve interests in the area of health access, particularly in regards to access to traditional healers. They contend that help for people living off-reserve is limited, despite the fact that there are off-reserve organizations, such as the Ontario Federation of Indian Friendship Centres, that help people living off-reserve. Further, even though chiefs and councils are elected to serve the interests of all band members, participants feel that the interests of off-reserve band members are not served in practice. 
Consequently, those members feel they encounter obstacles to receiving travel funding, and are forced to deal with various political/health organizations that may not be any better equipped to handle or solve their issues.

Participants highlighted the need for off-reserve band members to have someone to represent their interests on-reserve. One suggestion was to have a full-time, funded position within the band office to advocate in off-reserve affairs. The worker in the position would not have to report to chief and council, avoiding potential conflicts related to representing opposing interests. The worker would then attend chief and council meetings on behalf of off-reserve members, answer inquiries, research information, and help band members deal with health-related issues such as obtaining travel funding to see traditional healers. This position would, in some ways, be similar to those held by education counselors who stay in touch with students while they attend off-reserve schools and address their issues.

\section{Advocating Within the Medical Community}

Another form of advocacy was raised, in addition to creating advocacy on-reserve for those living off-reserve. Weengushk said that medical professionals have an obligation to advocate for traditional healing within the medical community:

Maybe it's the responsibility of physicians such as myself, who are a little more enlightened or aware of what's going on to advocate for that in provincial and national organizations; to say, look we need to have greater education about this stuff and endorse and support it. (Weengushk, interview, January 2010).

This type of advocating could help foster awareness about the legitimacy and role of traditional healing to First Nations people by bridging Western and the traditional forms of medicine. It would also, slowly, help to make changes in perception among regulated health professionals, clients (or applicants), and the non-Native community.

\section{Officially Recognizing Healers}

I think that they have to specifically recognize our traditional healers as just as legitimate as Western doctors. (Mohneeze, interview, September 2009)

Several participants maintained that the failure of the Canadian medical establishment to recognize traditional healers plays a role in the difficulty of off-reserve Aboriginal people to access travel dollars to see traditional healers. Native healers are constructed as different, and subordinate, to Western medicine and doctors, creating an unequal relationship in which doctors and medical professionals are the ones who oversee and grant permission for travel funding to be provided to those who seek access to it. In that role, doctors and medical professionals can grant or deny the existence of a medical condition and the receipt of travel funding. According to Amik:

I think it's a lack of understanding they have up there in regards to our healers and its importance. You know, you have to send in all this stuff from doctors saying why you have to attend (Amik, interview, March 2010). 
Related to the issue of recognition is that of healer compensation. Participants asserted that healers should be compensated at the same level as doctors and other medical professionals. In some cases this is already taking place in the US; when one particular recognized healer conducts his work within one of the Anishinabek bands in Sault Ste Marie, Michigan, for example, he is paid the same rate per day as a physician who comes into that community to perform medical services (as his oshkebewis [helper] told me). Within the geographic area of my Ontario research, this healer is in high demand and is compensated at a daily rate comparable to that of physicians. However, there is no generally established rate for traditional healers, and he is the exception to the rule. Myeengun stated that the healer works "on a sliding scale," depending on community funding availability. First Nation organizations typically ask healers how much their honorarium is and work to obtain the fee through funding agencies, such as AHWS, or through community fundraising (the average rate is $\$ 500 /$ day). If communities cannot provide this amount, there is often room for negotiation.

NIHB will not cover travel costs if healers make client referrals to other healers, because of their unequal standing within the Canadian medical system. Further, most doctors will not make referrals to healers because "[a] lot of them don't believe it, they don't understand it, they don't even know what it's about" (Mohneeze, interview, September 2009). One step suggested to help (potentially) resolve this issue is the creation of a "registry of healers" (Weengushk, interview, October 2009), which would contain an updated list of healers to whom doctors could make client referrals.

The registry could be based on the AFN's ethics model asserting ownership, control, access, and possession over research involving First Nations. For example, individual bands, tribal councils, or other First Nations organizations would have a decision-making role in, control of access over, and possession of this registry. The registry would also have to comply with ethical and other cultural protocols coming from traditional healers. Another model would be the self-organization of healers in different regions, as is done by the Union of Traditional Yagé Healers of the Colombian Amazon (UMIYAC) in South America. ${ }^{2}$ This group formally establishes and maintains its own practices and legitimacy of healers within traditional territories of Indigenous peoples within the Colombian Amazon region.

\section{Education}

We need to educate our own and learn to accept people who need the services even if they live off-reserve. (Aagimaak, interview, June 2010).

Participants have stated that there is a critical need for education in two main areas:

1. First Nation communities, and

2. the medical profession.

This recommendation occurred within the context of incorporating education policies that

$2 \mathrm{http} / /$ www.ayahuasca.com/spirit/primordial-and-traditional-culture/the-yurayaco-declaration-of-theunion-de-medicos-indigenas-yageceros-de-la-amazonia-colombiana-umiyac-yurayaco-colombia/ (accessed January 2011). 
balance out the present state of inequality within the medical establishment. One elder interviewed (Aagimaak) asserts that education needs to begin on-reserve with band and community members, health workers, and administration to focus on creating awareness that traditional healing services are available to the off-reserve membership. Health Canada and its medical staff should also travel to Friendship Centres and communities to see how healers work in order to develop an understanding and appreciation for their approach. This recommendation was echoed by others, who stated that this goal could be accomplished by bringing healers and medical staff together on a regular basis:

Have traditional healers come and talk with physicians and others, nurses, nurse practitioners, and saying: here's what we do. And, more than just one time, more like a regular session (Weengushk, interview, October 2009).

The concept of exposure to traditional healing programs is important not only during formal medical school education but also during in-service training, because "support from provincial and national organizations is non-existent for the most part" (Weengushk). Weengushk also suggested the following:

The availability of these services-where they might be. We don't have a central registry. We don't know where a traditional healer might be. There's lots of movement, there is significant turnover. It's a scarce resource. So, I think we need education about where these individuals are. We need to educate our population and our clients here and elsewhere that (1) this is a valuable aspect of their health care, and (2) that we encourage it (Weengushk, interview, October 2009).

Educating healers about how the pre-approval process works is also important. Because healers play a key role in whether or not a person gets travel reimbursement, healers should be aware of how things work. They should be knowledgeable enough to be able to advise people in what they need to do to obtain travel dollars to access them. Currently, many healers and their helpers are unaware of how the process works, either officially or in actual practice, while many others only know they have to sign the "healer verification form" so that a person can get travel dollars. If they are educated in how this process works, healers will be able to help people more substantially.

Education will help to dismantle the "boundaries" that prevent off-reserve band members from accessing traditional healing programs and services on-reserve. Those who should be educated include not only the band chief and council, band workers, and other employees, but on- and off-reserve band members. Education would also alleviate the ongoing lack of awareness, "understanding," or respect for Native ways of healing. More than one worker noted that they faced this lack when dealing with NIHB:

They need to know why we choose our healers - they don't have that understanding. They'll pay for us to go to Toronto to go and see heart specialists, cancer specialists and everything like that-mind you, it's still the same pay. They should be aware that we go see our healers for the same reasons and we should be allowed to do that and get that financial help when it's needed like that (Amik, interview, March 2010). 
Participants also emphasized that, while potentially unknown to NIHB, healing is a multifaceted endeavor that can take place on different levels involving the mind, body, and spirit. It can take the form of laughter, for example, because laughter can be used to treat people and help their health. Participants asserted that healing does not treat bodily ailments only, but encompasses treatment of the many different aspects of ourselves.

Furthermore, education would help to enlighten NIHB workers about different healing techniques and modalities that exist within Aboriginal communities. According to Mohneeze,

I think one of the things people have to understand is that the healers have different gifts, they deal with specific medicines, just like the physicians do, they specialize in different areas of health care. There are certain healers that will carry certain medicines for cancer, diabetes, and it's much along that same concept as the physician (Mohneeze, interview, September 2009).

Weengushk, a physician with an appreciation for traditional healers because of his experience and ongoing education, articulates the importance of this:

What I do is to deal with a single problem that is presented to me, whereas, working with a traditional healer allows me to access the whole individual. I'll give you an example-chronic physical pain is more than just physical. There's a lot of emotional, spiritual and historical pain there that we're missing. And for me, I think that's the critical role. I think we need to do a better job of fixing that-healing that, putting that gap back together. That's where I would like to see this go personally (Weengushk, interview, October 2009).

\section{Getting the Word Out: Promoting It}

Several participants observed that most people living off-reserve don't know what services are available to them. This situation is complicated by the fact that many workers at the NIHB, band office and community health centre levels, are not entirely clear either. There is a gap in communication between what is available and what people think is available. As one participant noted, "Communication is imperative" (Megis, interview, September 2009). Participants made several recommendations to increase the level of awareness about the availability of travel dollars to see traditional healers through a number of initiatives. These plans include "advertising," providing and distributing information, creating and distributing documents (such as a pamphlet) describing how the process works, and going into communities (including the off-reserve populations) to determine their "wants and needs."

Nodin, who is a front line worker, stated that lack of access to proper information prevents most people from accessing travel dollars (Nodin, interview, April 2010). She contended that providing contact telephone numbers is critical because most people don't have this information. Still another worker stated that "advertising" is needed to make people who live off-reserve aware that they can obtain travel funding to see traditional healers: 
A lot of people who live off-reserve are not aware that they can go and see a traditional healer because maybe they don't think it's a medical appointment. (Ookwemin, interview, July 2010)

Giizhik asserted that "attitude, awareness, education" are needed to make people offreserve know about what's available to them (Giizhik, interview, September 2009). One worker suggested putting information in the band's newsletter. This idea was rejected by others, who noted that band newsletters are often distributed only to those living on-reserve, except during years when band council elections are held. Bands and Health Canada could include this information on their websites, however.

Benashi stressed the importance of making information about "how the system works" available to medical transportation workers and band members off-reserve. Mohneeze echoes this, stating that one of the main problems is "lack of knowledge about how to access." Getting information out and making it available would include providing published documents on who to call and what to do. It was also suggested an addendum be made to current policy from NIHB, giving guidance to workers on how to proceed when they receive calls for this information.

Several participants (Myeengun, Benashi, Ookwemin, Weengushk, and others) supported the idea of creating an informational pamphlet containing relevant information to be distributed to bands, friendship centres, and First Nations Health organizations. This information could be provided in the form of a downloadable pdf on the Internet, a poster placed within doctors' examination rooms or health centres, or even as a simple one-page document asking, "Did you know that you are eligible for transportation dollars to access traditional healing?" (Benashi; Myeengun). Participants also emphasized that a booklet containing this information could be mailed by INAC to each person with Indian status to notify them of what they are entitled to. The information should also be provided to people who have had their status reinstated by Bill C-31, or others who have recently obtained Indian status. Currently, when an individual receives status, that person depends primarily on their band or some other organization to inform them of what they are entitled to. If these organizations choose not to provide such information or are unaware of what is available, then people stay uniformed.

Weengushk made another suggestion on how to better facilitate access to this information:

Have a registry of traditional programs for distribution. Have all the information in one packet. It would say, this is how an application is submitted for participation in the program. (Weengushk, interview, October 2009).

One participant cautioned against creating an informational pamphlet, however, as variations in how medical transportation requests are processed by First Nations would interfere with its effectiveness. "You'd have to contact each First Nation and see how they do it because everyone does it differently" (Ookwemin interview, July 2010). 
Improvements in access to timely and accurate health information were recommended because "a lot of people don't know what's covered and what is not." Changes take place, usually in the form of cuts to medical services, that people are not aware of. Each reserve should have a binder that is periodically updated with the latest changes to health policies affecting Non-Insured Health Benefits. This binder could be maintained by health centre clerks and used as a reference for those inquiring about available programs and services.

\section{Hiring Someone to Work on Medical Transportation}

They're so busy with the people they see all the time. That's hiring an extra body to come in and be the clerk. Just to work with Medical Services to get funding to go see healers - that would be a separate job because it's a lot of work-and it is because I know. (Amik, interview, March 2010)

Several participants commented that on-reserve health centres and off-reserve centres needed a position within their health units to handle travel and coordinating access to traditional healers. This position is needed because medical transportation clerks, who typically handle all aspects of transportation, are often overwhelmed by the workload of their position. As discussed in other segments of my study (Hankard 2012), one participant with over twenty years of experience as a front line worker described the complex and time consuming nature of the process, even when workers have a good understanding of it (M'kwa, interview, February 2010). Finally, it was remarked that reserve health centres would be more inclined to help band members living off-reserve if they had adequate staffing to support this initiative.

\section{A Policy for Handling Off-reserve Requests}

Like everything else, the government tells us what we have to do. (Benashi, interview, January 2010)

Wiigwaas, Ninatig, and Benashi all noted that Health Canada needs an official policy detailing how requests from off-reserve band members are handled. They also remarked that initiatives like this must emerge from official sources at the present time because First Nations are not yet able to establish such forms of governance. It was also asserted that complications may arise from this situation because NIHB is unlikely to embark on more expensive initiatives or to create potential controversy by taking over those areas of First Nations health that are currently managed by bands. Without formal guidelines in place, however, many people off-reserve remain disenfranchised. ${ }^{3}$ The way to formalize this policy, according to one participant, would be simply to create "an addendum to the current policy that says: If you have membership living off-reserve, here's the other side of this policy" (Benashi).

3 Just to clarify, the use of this term here differs from the historical definition of the term used by Indian Affairs and should not be confused with it. For example, in the past, becoming "enfranchised" meant losing one's Indian status, band membership, and so forth. 
The suggestion for a policy outlining the processing of off-reserve applications takes place in the context of a more general need for revising policies, regulations, and procedures relating to accessing travel funding. Not only is there a need for policy guidance to accompany the Medical Transportation Policy Framework, which organizes travel funding access, but also a need for a fundamental change in regulations that organize the work people do trying to access this funding.

\section{Making It User-Friendly}

They need to make it known - what they are and friendly-where people are able to understand it. Not technical, but in a kind of friendly way because a lot of our people can't read or write. (Ninatig, interview, June 2010)

Several participants remarked that the current process is so complex that it deters people from accessing healers, and there were several recommendations for making the process user-friendly. First, accessing travel dollars would be much simpler if the preapproval process were straightforward. People should be able to access travel dollars to see healers as easily as seeing a medical specialist or doctor. This would include accepting ceremonial reasons as valid for accessing travel funding. Funding for medical transportation, which is also in need of expansion, should be directly channeled to friendship centres and organizations involved in this process and be managed by them. That way, friendship centres and organizations could screen and organize travel to healers with their own budgets and not have to seek approval from NIHB.

The need to improve the "customer service" skills of NIHB workers and those working in band health centres/offices was also noted. People working in these positions should have a real desire to actually help people and not just be "collecting a paycheck" (Megis, interview, September 2009). Those individuals also need to understand that even if workers cannot help someone from off-reserve because they lack adequate information, they should behave with kindness. Two participants revealed that they underwent significant emotional distress because of the treatment they received from band and NIHB workers.

Several participants indicated the forms must be simplified. It is difficult for people to navigate the preapproval process partially because of the technical nature of the forms and related procedures, but also because information about how to fill out the forms is not well known or understood. The complexity of the forms should be dictated by the lowest level of formal education possessed by the applicants who will potentially use them. The forms should also be prepared in a way to ensure they are accessible by users who may be learning-disabled or functionally illiterate. The preapproval process, because it is multi-layered, requires applicants to possess both good interpersonal skills, as they have to interact with people in different positions (clerks, doctors, nurses, etc.), and the ability to understand health-related terminology. People often find it difficult to understand the technical requirements of such terms as "medical condition," for example, which appear within the preapproval form. 
One way to simplify the process is to include medical information on the new Indian status cards that ties directly into NIHB health databases. If this is done, people could visit any First Nation or off-reserve health centre, swipe their card through a reader, and have their NIHB medical information available. This system could enable users to bypass most of the forms that currently dictate this process. Because NIHB already maintains information about healers, verifying this information could be done quickly and travel reimbursement funding could be sent electronically to an individual's bank account for travel (Megis, interview, September 2009). ${ }^{4}$

Participants also noted that more inclusion and support for off-reserve band members is needed. Participants are unaware that funding for medical transportation is provided through two different funding pools (as discussed previously-one for those living onreserve and another for those living off-reserve) and maintain that it's unfair for them to be denied access to travel funding. Further, provincial travel grants, which are available to people seeking a Canadian medical specialist, are not available to people seeking the services of a traditional healer. This should also change. If healers are recognized as equals with doctors and medical specialists, this form of travel funding should be an option for people who wish to access their services.

Finally, inconsistencies in how bands and NIHB handle off-reserve requests must be eliminated. Because "each band does it differently," there is a need for additional policy guidance. Currently, NIHB may or may not process or approve requests depending on who one talks to, when they call, which region they call within and how the request is phrased. In some cases, even getting to the point where one can speak with a worker from NIHB can be a challenge.

\section{Conclusion}

During my study, front line workers, applicants, elders, healers and regulated health professionals made a number of recommendations for improving access for travel funding to see traditional healers. These recommendations outlined the usefulness of tenacity, confrontation, and communication, as well as bringing more information, advocacy, and education to band members, regulated health professionals, and traditional healers (both on- and off-reserve). These strategies and recommendations emerged from the standpoint of people who have engaged with the Non-Insured Health Benefits system, in some cases, for over twenty years. They illustrate the importance of finding the "wants and needs of the community" (Myeengun, interview, January 2010) when seeking solutions to ongoing, pervasive problems facing First Nations people. Because these recommendations emerge from a grassroots level, they contain insight and information that can be developed and put to good use within the First Nations healthcare system.

These recommendations from participants all have one thing in common-they highlight the need for change in how access to travel funding is organized. As the program

4 It is worth noting that the intention of this is not to increase the range of information collected by the government or the range of its surveillance practices. 
currently operates, it can be a challenge for a person living off-reserve not only to find out about it and how it works, but to navigate though the many other channels required to complete forms when that does happen: it can be overwhelming. Given these challenges, the need for grassroots solutions to this problem becomes painfully clear and necessary. 


\section{Bibliography}

Bresalier, M., L. Gillis, C. McClure, L. McCoy, et al. 2002. Making Care Visible: Antiretroviral Therapy and the Health Work for People Living with HIV/AIDS. Toronto: The Making Care Visible Working Group.

Hankard, M. 2012. Accessing Traditional Healer Travel Funding: It's Not "The Same for Everybody." Laurentian University, Department of Human Studies.

Health Canada. 2005. Non-Insured Health Benefits Program. Medical Transportation Policy Framework. Section 8. Traditional Healer Services Travel Policy. Accessed 17 November 2013. http://www.hc-sc.gc.ca/fniah-spnia/pubs/nihb-ssna/_ medtransp/2005_med-transp-frame-cadre/index-eng.php\#a8.

Smith, D.E. Writing the Social: Critique, Theory and Investigations. Toronto: University of Toronto Press, 1999.

Statistics Canada. 2006a. Profile of Aboriginal Children, Youth and Adults, Registered offreserve Indians, Ontario. Accessed May 9, 2009. http://www12.statcan.gc.ca/ census-recensement $/ 2006 / \mathrm{dp}-\mathrm{pd} / 89-635 / \mathrm{P} 4 . \mathrm{cfm}$ ?Lang=eng\&age=3\&ident_ $\mathrm{id}=7 \& \mathrm{~B} 1=0$ \&geocode $1=041$ \&geocode $2=000$.

-_- 2006b. Aboriginal People in Canada in 2006: Inuit, Metis and First Nations, 2006 Census: First Nations People. "Fewer First Nations People Live on Reserve than Off Reserve." Accessed January 10, 2009. http://www12.statcan.ca/english/census06/ analysis/aboriginal/fewer.cf.

Wilson, S. 2008. Research is Ceremony: Indigenous Research Methods. Halifax and Winnipeg: Fernwood.

\section{Interviews}

M'Sheeken (Turtle) is First Nations-kwe and lives off-reserve in northern Ontario. She accessed the Medical Transportation Policy to obtain travel funding to see a traditional healer and described her experiences. (September 12, 2009)

Mohneeze (Mary) is First Nations-kwe and has worked in First Nations health and advocacy organizations in Ontario for over twenty years. (September 16, 2009)

Megis (Shell) is First Nations from a reserve in northern Ontario. He lives off-reserve and obtained travel funding to see a traditional healer from off-reserve. (September 19, 2009)

Giizik (Cedar) is First Nations-kwe and has worked in First Nations health and advocacy organizations in Ontario for over twenty years. (September 23, 2009)

Weengushk (Sweetgrass) is a non-Native physician working with First Nations people in Ontario. (October 1, 2009)

Benashi (Bird) is First Nations-kwe and has worked in First Nations health and advocacy organizations in Ontario for over 15 years. (January 21, 2010)

Myeengun (Wolf) is a First Nations elder and healer who has been involved in First Nations health and wellness programs and services for over forty years. (January 21, 2010) 
M'kwa (Bear) is First Nations-kwe and has been worked in the field of First Nations health for over twenty years. (February 18, 2010)

Amik (Beaver) is First Nations-kwe and has worked in the field of traditional health and wellness for about fifteen years. (March 3, 2010)

Asemaa (Tobacco) is First Nations-kwe and has been a front-line worker in First Nations health organizations for over twenty years. (April 7, 2010)

Nodin (Wind) is First Nations-kwe and has worked in First Nations health programs for over twenty years. (April 12, 2010)

Ninatig (Maple) is First Nations-kwe and has worked as a healer's helper and front-line worker in the field of traditional health for over twenty years. (June 23, 2010)

Aagimaak (Black Ash) is an Anishinabek elder and healer who has worked with First Nations people for over 30 years. (June 30, 2010)

Ookwemin (Black Cherry) is First Nations-kwe and lives off-reserve in northern Ontario. She accessed the Medical Transportation Policy to obtain travel funding to see a traditional healer and described her experiences. (July 7, 2010) 